\title{
RASHOMON: A PERCEPÇÃO E A CONSTRUÇÃO DA NORMA DO CASO CONCRETO
}

\author{
RASHOMON: THE PERCEPTION AND THE CONSTRUCTION OF THE RULE OF THE CASE
}

Priscilla Maria Santana Macedo ${ }^{1}$

Rafael Marcílio Xerez ${ }^{2}$

Resumo: $\bigcirc$ filme japonês Rashomon (1969) retrata o relato de um crime de estupro de uma mulher, seguido do assassinato de seu marido, um samurai, na perspectiva de quatro pessoas diferentes. As versões completamente contraditórias ilustram perfeitamente a influência da percepção na construção do "enunciado de fato", que é produto da percepção de um sujeito do "fato" que ocorre no mundo fenomênico. Das interferências e influências que recaem sobre a percepção, surge a problemática referente à busca pela verdade real, especialmente em âmbito jurídico, na aplicação da norma ao caso concreto, em que o Juiz recebe um fato por meio de relatos, muitas vezes divergentes, baseados em diferentes percepções. Destarte, a partir de uma análise ilustrativa da obra cinematográfica Rashomon, buscou-se analisar questões referentes à concretização de direitos mediante a aplicação da norma jurídica a casos concretos de forma a aproximar-se da verdade real, considerando que os elementos que compõem o caso se baseiam na percepção.

Palavras-chave: Rashomon. Percepção. Enunciado de fato. Aplicação da norma jurídica. Concretização de direitos.

\begin{abstract}
The Japanese movie Rashomon (1969) portrays the story of a crime of rape of a woman, followed by the murder of her husband, a samurai, from the perspective of four different people. The completely contradictory versions perfectly illustrate the influence of perception in the construction of the "statement of the fact", which is the product of the perception of a subject about the "fact" that occurs in the phenomenal world. Interference and influences that reflects on the perception, brings the issue regarding the pursuit of the real truth, especially in the legal field, in the application of the rule to the case in which the judge receives a fact through narratives, often divergent, based on different perceptions. From an illustrative analysis of the cinematographic work Rashomon, this study aimed to analyze issues related to the realization of rights by applying the legal rule to specific cases in order to approach the real truth, considering that the elements of the case are based on perceptions.
\end{abstract}

Keywords: Rashomon. Perception. Statement fact. Application of the legal rules. Realization of rights.

\footnotetext{
1 Mestranda do Programa de Pós-Graduação em Direito pela Universidade de Fortaleza; priscillasantanamacedo@gmail. com

2 Doutor em Direito pela Universidade Federal da Bahia; Mestre em Direito pela Universidade Federal do Ceará; Professor dos Cursos de Pós-Graduação em Direito (Doutorado e Mestrado) e Graduação em Direito da Universidade de Fortaleza; Avenida Washington Soares, 1321, Edson Queiroz, 60811-908, Fortaleza, Ceará, Brasil; rmxerez@secrel.com.br
} 


\section{Introdução}

A percepção não é uma atividade passiva, mas um processo construtivo que passa por diferentes momentos. Entre estes, o momento da "sensação", ou forma pela qual o sujeito que percebe a situação ou objeto é afetado; o das "associações", na medida em que as percepções vêm sempre em meio a um horizonte de sentidos; o da "projeção de recordações", que visa preencher as lacunas perceptivas; o da "atenção", que "recorta" o objeto/fato percebido a partir de razões subconscientes; e o do "juízo", que implica uma tomada de posição em relação ao objeto/fato. Assim, o "real" é um tecido sólido e pressuposto da percepção, que engloba reações a fenômenos reais que perpassam da esfera da realidade para a mente, adquirindo, nesse "trânsito", aspectos inerentes ao sujeito que percebe e às condições em que ocorre a percepção.

Dessas interferências que recaem sobre a percepção, decorre a inevitável diferença entre "fato" e "enunciado de fato", posto que o "fato" é fenômeno que ocorre no mundo, e "enunciado de fato" é o produto da percepção do sujeito que o narra. Essas constatações levam à problemática da busca pela verdade real, especialmente em âmbito jurídico, em que quem decide a solução dos casos concretos - o juiz - é terceiro alheio aos fatos e constrói sua percepção a partir das narrativas das partes envolvidas. Assim, questiona-se: como saber se o enunciado do fato expressa a verdade real ou em que se distancia dela? Existe uma verdade real absoluta, considerando-se que as percepções são construídas e afetadas por diversos fatores?

Os direitos do homem são marcados pela historicidade, característica que decorre da complexidade e dinamicidade das relações sociais e situações fáticas existentes. Por tal razão, embora não se possa admitir a ausência de um regramento determinado, este não é capaz de abranger a totalidade das condutas humanas, dando margem à necessidade interpretativa da ciência jurídica. Tem-se, portanto, o texto normativo, que é um enunciado linguístico, e tem-se a norma, que é o produto da interpretação do enunciado, este que, por sua vez, em conjunto com a realidade fática, conduz à construção da norma de decisão, ou norma do caso concreto, que garante a concretização do direito mediante a solução de casos concretos.

A tarefa de construção da norma do caso concreto compete ao juiz que recebe o enunciado do fato, ou os enunciados do fato e, durante o processo, lapida esse enunciado para aproximá-lo o máximo possível da verdade real, por meio das provas colhidas. A partir de então, adapta a situação fática à norma jurídica preexistente. Os enunciados de fato, contudo, inclusive aquele elaborado pelo juiz depois de lapidar o enunciado de fato "bruto" fornecido pelos relatos, baseiam-se em percepções. Dessa feita, tem-se o seguinte questionamento: como concretizar direitos por meio da aplicação da norma jurídica a casos concretos de forma a aproximar-se da verdade real, quando os elementos que compõem o caso se baseiam em percepções que podem não representar a verdade real?

O filme japonês Rashomon (1969), dirigido por Akira Kurosawa, ilustra perfeitamente a problemática abordada no presente artigo, na medida em que retrata a narrativa de um crime de 
estupro de uma mulher e consequente assassinato de seu esposo, um samurai, a partir do relato de quatro pessoas: um lenhador, que teria encontrado o corpo; o bandido Tajomaru; a esposa do samurai; e o próprio falecido, que externou sua versão dos fatos através de um medium. Todas as versões são contraditórias entre si e, ao final, não é possível estipular qual seria a que mais se aproxima da verdade. A obra cinematográfica faz emergir uma discussão acerca da possibilidade de se obter a verdade sobre determinado evento.

Com a presente pesquisa objetiva-se, portanto, tecer considerações acerca da percepção e da construção da norma do caso concreto, a partir de um relato inicial da obra Rashomon, analisando a problemática referente à percepção na construção da norma do caso concreto. Quanto aos aspectos metodológicos, a presente pesquisa segue uma abordagem qualitativa, descritiva e exploratória no que se refere aos objetivos; bibliográfica, quanto ao tipo; pura, quanto ao manejo dos resultados, colhidos a partir de um estudo descritivo-analítico, desenvolvido por meio de pesquisa teórica.

$\mathrm{O}$ artigo em tela desenvolve-se em três eixos fundamentais. Primeiro, faz-se um relato da obra cinematográfica Rashomon, visando proporcionar uma melhor compreensão acerca do problema a ser abordado nos tópicos posteriores. Em seguida, trata-se da percepção, conforme Merleau-Ponty, e da construção do enunciado do fato, abordando a diferença entre o fato real e o enunciado deste, bem como sobre os fatores e características que modificam a percepção dos fatos conforme os sentidos. Por fim, o estudo trata da construção da norma do caso concreto, abordando a historicidade dos direitos, questões referentes ao texto e à norma, bem como ao processo de concretização do direito mediante a interpretação da norma jurídica em conjunto com a análise fático-probatórica.

\section{A Problemática da Percepção no Filme Rashomon}

Rashomon (1969) é um filme japonês escrito e dirigido por Akira Kurosawa, baseado em dois contos de Ryunosuke Akutagawa (2008). Do conto homônimo, aproveitou-se a locação onde passa a maior parte do filme, qual seja o Rashomon, Portal que se situava na entrada da atual Cidade de Quioto. Referida Cidade teria sofrido terremotos, redemoinhos, incêndios e fome, o que culminou na "enorme desolação no centro da Capital", situação de abandono que se estendeu ao Portal Rashomon, o qual passou a ser habitado somente por raposas, texugos e ladrões. Eventualmente, virou hábito abandonar naquele Portal cadáveres não reclamados (AKUTAGAWA, 2008, p. 27-28).

O segundo conto, denominado de Dentro do bosque, determina os personagens e a parte principal da trama. Esse conto transcreve os depoimentos do lenhador, do monge budista peregrino (que no filme é um sacerdote), do policial e de uma velha - sogra do falecido (ausente na narrativa do filme) -, as confissões de Tajomaru e da esposa do samurai morto, bem como a narrativa do próprio samurai, através de um médium, sobre as circunstâncias em que teria ocorrido o crime que findou com sua morte (AKUTAGAWA, 2008, p. 37-51). 
O filme tem início em um cenário de tempestade, em que três homens - um lenhador, um sacerdote e um camponês - buscam abrigo nas ruínas do Portal de Rashomon. Enquanto aguardam a tempestade ceder, o sacerdote e o lenhador, horrorizados e confusos com uma "história estranha" que teriam visto e ouvido no jardim do palácio da justiça, naquele mesmo dia, passam a contar ao camponês detalhes do julgamento que testemunharam, envolvendo o estupro de uma mulher e o assassinato de seu marido, um samurai. A partir de então, a história é contada em flashbacks que se referem tanto ao momento dos crimes quanto ao julgamento, em que algumas pessoas contam suas versões ou testemunhos, não sendo possível ver ou ouvir a autoridade que comanda a oitiva dos depoimentos.

O lenhador inicia a narrativa contando que três dias antes, enquanto buscava madeira nas montanhas, encontrara, no meio da floresta, o chapéu de uma mulher preso em um galho. Logo em seguida, encontrara um boné de samurai, que havia sido pisoteado. Afirma ter seguido, pois, caminhando em direção a um objeto pequeno, preso nas folhas - um amuleto brilhante com forro vermelho - e, sem perceber, tropeçara no cadáver do samurai. Assustado, diz ter derrubado tudo o que carregava consigo e ter corrido o mais depressa que pode para noticiar tal fato às autoridades. Três dias depois disso, fora chamado para testemunhar sobre o que vira.

O sacerdote, por sua vez, também ouvido no julgamento, conta que conhecera o homem assassinado ainda em vida, três dias antes, pela tarde, quando o encontrara na estrada, carregando uma espada, um arco e flechas e puxando um cavalo, o qual era montado por uma mulher cujo rosto estava coberto por um véu. Depois do sacerdote, um policial afirmou ter capturado Tajomaru, um notório bandido, dois dias antes, ao entardecer, nas margens de um rio, quando este fora derrubado do cavalo que montava. Afirma que, quando localizou o bandido, este portava, além do cavalo, 17 flechas com penas de águia e um arco de couro, todos pertencentes ao de cujus.

O bandido Tajomaru é ouvido em seguida e, negando ter caído do cavalo, passa a narrar a sua versão do crime, afirmando que nada esconderá por saber que cedo ou tarde terão "o seu pescoço". Tajomaru confessa ter assassinado o samurai, narrando que o teria visto com sua esposa três dias antes e que teria se interessado por esta, decidindo capturá-la, ainda que, para tanto, fosse necessário matar seu marido, muito embora sua primeira intenção fosse levá-la sem matá-lo. O bandido afirma, portanto, que correu para alcançar o casal e ludibriou o samurai a acompanhá-lo para um arvoredo atrás da montanha, sob a alegativa de que teria espadas e espelhos para vender-lhe a baixo custo. Ao chegar no mencionado local, contudo, teria atacado o samurai pelas costas, dominando-o e o amarrando com uma corda. Disse o bandido que correu para encontrar a esposa do samurai e lhe falou que ele teria passado mal nas montanhas. A preocupação da mulher com o marido teria feito com que ele invejasse e odiasse o homem, nutrindo um desejo de vê-lo humilhado.

Os dois teriam corrido, portanto, para encontrar o samurai e, enquanto corriam, a mulher teria perdido o seu chapéu. Ao ver o marido amarrado, a mulher ferozmente teria atacado o bandido com um punhal, e, durante a luta corporal de ambos, Tajomaru a teria dominado e beijado à força, ocasião em que ela não reagiu, largando o punhal e entregando-se a ele. Desta feita, alcançando o seu obje- 
tivo de possuir a mulher sem matar seu marido, Tajomaru afirma ter ido embora, sendo interrompido, contudo, pela mulher, que lhe pediu que duelasse com seu marido, para ir embora com o sobrevivente, ou que a matasse, pois seria melhor morrer do que saber que tinha "conhecido dois homens". Ainda de acordo com a narrativa do bandido, este teria soltado o samurai e duelado com ele até conseguir matá-lo. Perguntado sobre a mulher, o bandido pensa um pouco e diz que, ao final da luta, procurou-a e não a encontrou, pelo que supôs que tivesse fugido, visto que encontrou somente seu cavalo. Perguntado sobre a espada do samurai, disse a ter trocado por bebida na cidade; e sobre o punhal da mulher, afirma que o teria esquecido no local e que isso teria sido seu maior erro, pois ele parecia valioso.

Enquanto narra os detalhes do julgamento no Portal de Rashomon, o lenhador diz que as narrativas do bandido e da mulher do samurai são mentirosas, ao passo que o camponês concorda dizendo que "é humano mentir". O sacerdote, então, conta que a versão da mulher do morto é divergente da versão de Tajomaru, de modo que ela sequer demonstrou a "ferocidade" referida pelo bandido. Passa, pois, o sacerdote, a narrar o que viu a mulher contar no jardim do palácio da justiça.

A viúva do samurai narra que Tajomaru, depois de forçá-la a entregar-se a ele, teria gargalhado de forma debochada de seu marido, o qual, horrorizado, lutava, tentando livrar-se das cordas, contudo, deixando-as mais apertadas com seus movimentos. Afirmou que tentou chegar perto de seu esposo, quando foi derrubada pelo bandido, o qual tomou a espada do samurai, deu uma gargalhada e fugiu. A mulher diz ter abraçado o marido, que olhava para ela com um olhar "frio", de repugnância. Diz ter implorado para que ele parasse de olhar daquela forma para ela, depois ter cortado as cordas que o amarravam e ter the oferecido o punhal para que ele a matasse. $O$ samurai teria permanecido inerte e ela teria continuado implorando que ele parasse de a condenar com seu "silêncio". A mulher afirmou que "deve ter desmaiado" e, ao acordar, teria visto seu punhal no peito de seu marido morto, não se recordando de como teria deixado o bosque; tinha somente a lembrança de um lago e afirmou que teria tentado tirar a própria vida de diversas formas.

O camponês, que escutava atentamente a narrativa do sacerdote, interrompe afirmando que as mulheres usam suas lágrimas para enganar a todos, inclusive elas mesmas. $O$ sacerdote, respondendo-o, refere-se a uma "história do homem morto", que teria sido contada através de um médium. O lenhador, confuso, diz que a história do morto também é mentira, e o sacerdote discorda, dizendo não acreditar que homens mortos mentem. A pedido do camponês, o sacerdote continua a narrativa, dizendo que, no jardim do palácio da justiça, o médium fez um ritual invocando o espírito do samurai, passando a falar com sua voz.

O falecido teria contado que, depois de atacar sua esposa, o bandido tentou consolá-la, dizendo que a teria atacado por amor e que, depois de "desonrada", ela não poderia mais pertencer a seu esposo. Afirma que sua esposa teria se deixado levar pelos argumentos do bandido, pedindo que ele a levasse para onde quisesse. Antes de partir, contudo, teria pedido que Tajomaru matasse o samurai, ao passo que o bandido, indignado, a teria derrubado e perguntado a seu esposo o que desejava que fosse feito a ela. Diz que a esposa teria conseguido fugir e que Tajomaru teria a perseguido; muitas horas de- 
pois, este teria retornado, cortado as cordas que amarravam o samurai e dito que a mulher havia fugido e que seguiria seu próprio destino, indo embora levando as duas espadas. O samurai teria encontrado, então, o punhal que pertencia à sua esposa e o teria cravado no próprio peito. Disse que, então, alguém teria se aproximado silenciosamente e arrancado o punhal de seu peito.

O lenhador segue inconformado com tais versões, insistindo que o samurai fora morto com uma espada e não com um punhal. Diante da reação do lenhador, o camponês, interessado e desconfiado, diz que parece que o lenhador viu tudo o que aconteceu, e pergunta o que ele teria visto e por que não teria contado no jardim do palácio da justiça. $O$ lenhador justificou que não queria "se envolver" e disse que, na verdade, teria encontrado um chapéu de mulher na floresta e que, logo após, teria ouvido o choro de uma mulher. Escondido atrás de um arbusto, afirma ter visto um homem amarrado, uma mulher chorando e Tajomaru, que implorava a mulher por perdão. De acordo com a nova versão do lenhador, enquanto Tajomaru implorava que a mulher fosse embora com ele, ela teria pego seu punhal e cortado as cordas que prendiam o samurai, dando a entender que os homens deveriam duelar para decidir seu destino. $\bigcirc$ samurai, ainda de posse de sua espada, teria dito não querer arriscar sua vida por aquela mulher que esteve com dois homens. $\bigcirc$ bandido, pois, teria começado a caminhar para deixar o local, e a mulher teria começado a chorar e depois a rir desesperadamente, acusando-os de "fracos". As provocações da mulher teriam feito com que os homens iniciassem uma luta que findou com Tajomaru matando o samurai com a espada. $O$ bandido teria tentado se aproximar da mulher, que teria fugido correndo, e desistiu de ir atrás dela, recolhendo as duas espadas e partindo sozinho.

O camponês duvida da versão contada pelo lenhador, que afirma ter visto tudo com "os próprios olhos". O sacerdote, exaltado, diz que aquilo é horrível e que "se os homens não confiam uns nos outros, a Terra pode ser um inferno", preferindo acreditar nos homens e dizendo não querer que a Terra fosse um inferno.

Enquanto discutem, os três ouvem o choro de um bebê e, ao encontrá-lo, o camponês tenta furtar um quimono que o envolvia. $O$ sacerdote e o lenhador se revoltam com aquela conduta e, enquanto o sacerdote pega o bebê em seu colo, o lenhador acusa o camponês de ser malvado. $\bigcirc$ camponês diz que, se não fosse ele, outra pessoa levaria o quimono e que malvados, na verdade, seriam os pais da criança que a abandonaram naquele Portal. O lenhador tenta impedir o camponês, que insiste que o egoísmo é necessário à sobrevivência, levando o lenhador à conclusão de que todos são egoístas e desonestos - o samurai, sua esposa, o camponês e o bandido. O camponês retruca uma vez mais, afirmando ser também o lenhador um desonesto, pois sabia que este teria roubado o punhal da esposa do samurai. O lenhador, envergonhado de seus próprios atos, apenas abaixa a cabeça.

O camponês vai embora com o quimono da criança, rindo de forma debochada e, quando cessa a chuva, o lenhador tenta pegar a criança do colo do sacerdote, que se recusa a entregá-la. $\bigcirc$ lenhador, então, afirma que já tem seis filhos e que um a mais não faria diferença. $\bigcirc$ sacerdote se diz envergonhado com os atos do lenhador, que concorda e diz que depois de um dia daqueles é inevi- 
tável suspeitar dos outros, mas que ele é quem deveria estar envergonhado. $O$ filme termina com o sacerdote reconhecendo a decência do lenhador, agradecendo por poder manter sua fé nos homens, entregando a criança a ele, que deixa o Portal com o bebê no colo.

O filme, portanto, chega ao fim sem que se determine qual das versões sobre o fato seria a verdadeira. Inclusive, a versão do próprio lenhador é duvidosa, na medida em que o camponês descobre, ao final, que este teria furtado o punhal pertencente à esposa da vítima e mentido sobre tal fato. Sugere, pois, a impossibilidade de se obter a verdade sobre um evento.

\section{A Percepção conforme Merleau-Ponty e o Enunciado do Fato}

A percepção abrange um processo construtivo que perpassa por diferentes momentos. Um deles é a "sensação", que é "a maneira pela qual sou afetado e a experiência de um estado de mim mesmo", ou seja, aquilo que é percebido passa a ter um significado para o sujeito cognoscente, deixando de existir meramente no plano objetivo (MERLEAU-PONTY, 2006, p. 23). Frise-se, outrossim, que "os processos sensoriais não são inacessíveis a influências centrais", ou seja, a forma como percebemos um objeto pode ser diretamente afetada por condições, como distância ou iluminação, por exemplo (MERLEAU-PONTY, 2006, p. 29).

As sensações e imagens "aparecem sempre em um horizonte de sentido", de modo que a significação do objeto percebido "está pressuposta em todas as associações, quer se trate da sinopse de uma figura presente ou da evocação de experiências antigas." (MERLEAU-PONTY, 2006, p. 38). Assim, ao perceber algo, inevitavelmente associamos o significado do que é percebido a imagens ao redor, ou mesmo a imagens guardadas em nossa memória. Merleau-Ponty (2006, p. 42), ao referir-se à associação, afirma que:

Portanto, a associação nunca funciona como uma força autônoma; nunca é a palavra proposta que, como causa eficiente, "induz" a resposta, ela só age tornando uma intenção de reprodução provável ou tentadora, só opera em virtude do sentido que adquiriu no contexto da experiência antiga e sugerindo o recurso a essa experiência, ela é eficaz na medida em que o sujeito a reconhece, a apreende sob o aspecto ou sob a fisionomia do passado. Se enfim se quisesse fazer intervir, em lugar da simples contiguidade, a associação por semelhança, ver-se-ia ainda que, para evocar uma imagem antiga à qual ela de fato se assemelha, a percepção presente deve ser posta em forma, de maneira a se tornar capaz de trazer essa semelhança.

O mesmo autor explica que, muitas vezes, o fenômeno perceptivo não é completo, de modo que "para vir a completar a percepção, as recordações precisam ser tornadas possíveis pela fisionomia dos dados", ou seja, "antes de qualquer contribuição da memória, aquilo que é visto deve presentemente organizar-se de modo a oferecer-me um quadro em que eu possa reconhecer minhas experiências anteriores." As lacunas devem ser preenchidas, portanto, por meio de uma projeção de recordações (MERLEAU-PONTY, 2006, p. 43-44). 
Sintetiza, portanto, Merleau-Ponty (2006, p. 47-48):

Perceber não é experimentar um sem-número de impressões que trariam consigo recordações capazes de completa-las, é ver jorrar de uma constelação de dados um sentido imanente sem o qual nenhum apelo às recordações seria possível. Recordar-se não é trazer ao olhar da consciência um quadro do passado subsistente em si, é enveredar no horizonte do passado e pouco a pouco desenvolver suas perspectivas encaixadas, até que as experiências que ele resume sejam como que vividas novamente em seu lugar temporal. Perceber não é recordar-se.

Essas associações, projeções e sensações não são somente inerentes ao objeto percebido, ou a seu significado, de modo que o sujeito que percebe o objeto participa ativamente na construção perceptiva mediante o que se pode denominar de "atenção" e "juízo". A "atenção", nesse contexto, seria "a constituição de um objeto novo que explicita e tematiza aquilo que até então só se oferecera como horizonte indeterminado." (MERLEAU-PONTY, 2006, p. 58). A atenção seria, portanto, um ato (re)criativo, na medida em que a partir da percepção de um objeto por um sujeito, por alguma razão consciente ou subconsciente, onde antes havia um horizonte indeterminado, com a atenção, passa a verificar-se um "recorte", um novo objeto. ○ "juízo", por sua vez, vem para "explicar o excesso da percepção sobre as expressões retinianas", ou seja, em vez de uma "reflexão autêntica" sobre a percepção, tem-se a interferência no significado do percebido por meio da "tomada de uma posição", tratando-se, além da "sensação pura", de um entendimento ou interpretação da percepção (MERLEAU-PONTY, 2006, p. 62). A percepção, portanto, "abre-se sobre coisas", ou seja, "se orienta, como para seu fim, em direção a uma verdade em si em que se encontra a razão de todas as aparências." (MERLEAU-PONTY, 2006, p. 85).

Assim, a percepção seria uma reação a fenômenos reais que transporia a esfera da realidade para a mente, de modo a formar uma concepção da realidade que contém aspectos inconscientes e inúmeros fatores não conhecidos, de modo que o homem jamais percebe plenamente algo, posto que seus próprios sentidos limitam sua percepção (JUNG, 2008, p. 21-23). Nossa percepção pode ser alterada não apenas pela limitação dos sentidos, mas também pela ilusão, que se faz passar por uma percepção autêntica (MERLEAU-PONTY, 2006, p. 45). Tem-se, portanto, que a percepção sofre inquestionáveis interferências advindas do meio, dos sentidos de quem percebe, de fatores conscientes ou inconscientes de quem percebe, da ilusão, ou da ideia de uma percepção real. Assim, por óbvio, ao descrever um determinado objeto, ou narrar uma situação, cada sujeito o faz de uma forma própria, de acordo com os seus sentidos e a sua perspectiva, que é formada por elementos conscientes e inconscientes.

Por essa razão, Larenz (1997, p. 307) explica que não se pode confundir a situação de fato como enunciado com a situação de fato enquanto fenômeno da vida, a que se refere o enunciado. $\bigcirc$ enunciado do fato, portanto, distancia-se do fato real na medida em que a percepção do sujeito que o narra sofre interferências de diversas naturezas, conforme já explicado, de modo que o enunciado do fato é apenas a forma pela qual percebeu o fato o sujeito cognoscente. 
Tais questões relativas à percepção problematizam a questão da busca pela verdade real, especialmente em âmbito jurídico, quando um terceiro alheio à situação (o Juiz) precisa construir, por meio de diversos enunciados de fato e de provas, um enunciado de fato. Afinal, considerando que cada sujeito atribui um determinado sentido ao fato ou objeto percebido, como saber se aquele enunciado expressa a verdade ou em que se distancia dela? Existiria uma verdade absoluta e real? Nesse sentido, Ferrajoli (2002, p. 48) expressa que:

A "verdade" de uma teoria científica e, geralmente, de qualquer argumentação ou proposição empírica é sempre, em suma, uma verdade não definitiva, mas contingente, não absoluta, mas relativa ao estado dos conhecimentos e experiências levados a cabo na ordem das coisas de que se fala, de modo que, sempre, quando se afirma a "verdade" de uma ou de várias proposições, a única coisa que se diz é que estas são (plausivelmente) verdadeiras pelo que sabemos sobre elas, ou seja, em relação ao conjunto dos conhecimentos confirmados que delas possuímos.

Tratando da busca da verdade, Nietzsche (2007, p. 37), explica que "as verdades são ilusões das quais se esqueceu que o são." Isso porque "acreditamos saber algo acerca das próprias coisas, quando falamos de árvores, cores, neve e flores, mas, com isso, nada possuímos senão metáforas das coisas, que não correspondem, em absoluto, às essencialidades originais" (NIETZSCHE, 2007, p. 33-34), ou seja, o homem usa a linguagem para exprimir sensações que se referem às relações entre as coisas e ele mesmo, e não às coisas propriamente ditas, assim, retrata a sua verdade de modo unilateral, conforme seus interesses e percepções.

Para Habermas (2004b, p. 45-46), a "verdade de um enunciado parece poder ser garantida apenas por sua coerência com outros enunciados, já aceitos", no entanto, questionando a própria assertiva, ressalta que:

Mesmo o acordo alcançado por meio de uma justificação "construtiva" e que provisoriamente conclui um discurso de modo convincente resulta num saber do qual os envolvidos, em seu papel de participantes da argumentação, podem saber que ele é falível e perfectível. Os atores que chegam a um bom termo com o mundo nutrem-se de suas certezas de ação, mas, para os sujeitos que, na moldura dos discursos, se certificam reflexivamente de seu saber, a verdade e a falibilidade de um enunciado são dois lados da mesma moeda. (HABERMAS, 2004b, p. 52).

O conceito de verdade é, portanto, frágil, e nem sempre a verdade pode ser alcançada. A obra cinematográfica analisada na primeira seção do presente estudo retrata perfeitamente como o fenômeno da percepção, bem como a interferência de fatores diversos (como no caso do lenhador que voluntariamente omitiu e modificou em sua narrativa o que efetivamente teria presenciado para "não se envolver"), pode fazer com que o enunciado do fato não retrate de forma fidedigna o fato efetivo. A ausência de uma constatação, ao final do filme, de qual das versões seria efetivamente a verdade sobre o crime que vitimou o samurai demonstra, outrossim, essa fragilidade da verdade, bem como a influência da percepção do sujeito. 
Em âmbito jurídico, a tendência hermenêutica converge para o uso do procedimento argumentativo, este que, para Habermas (2004a, p. 60-61), embora não seja capaz de alcançar em definitivo a verdade, é o único meio capaz de alcançar a aceitabilidade racional desta. Contudo, o próprio autor ressalta a fragilidade deste procedimento ao expor que:

[...] até bem pouco tempo eu procurava explicar a verdade em função de uma justificabilidade ideal. De lá para cá, percebi que essa assimilação não pode dar certo. Reformulei o antigo conceito discursivo de verdade, que não é errado, mas é pelo menos incompleto. A redenção discursiva de uma alegação de verdade conduz à aceitabilidade racional, não à verdade. Embora nossa mente falível não possa ir, além disso, não devemos confundir duas coisas. Resta-nos assim a tarefa de explicar por que os participantes de uma discussão se sentem autorizados - e supostamente o são de fato - a aceitar como verdadeira uma preposição controversa, bastando para isso que tenham, em condições quase ideais, esgotado todas as razões disponíveis a favor e contra essa proposição e assim estabelecido a aceitabilidade dela.

Ocorre que, contudo, nem se pode considerar a existência de um sistema integralmente constituído em torno da verdade, pois tal seria uma utopia, e nem se pode admitir a não consideração da verdade, posto que se estaria considerando um sistema de arbitrariedade. Por esse motivo, a falibilidade do método de busca da verdade não deve ser colocada como óbice à persecução desta, fazendo-se necessário buscar a aproximação máxima de uma noção de verossimilhança, a partir das provas e enunciados de fato que permeiam o objeto de uma determinada investigação (FERRAJOLI, 2002, p. 38).

\section{A Construção da Norma do Caso Concreto}

Larenz (1997, p. 261-263) expressa que o Direito é um fenômeno complexo "que se manifesta em distintos planos do ser, em diferentes contextos", que apresenta íntima relação com a existência social do homem e apresenta "a estrutura temporal da historicidade", ou seja, permanece durante um tempo e continuamente se adapta às variações do tempo histórico, que tem a marca do homem. Nesse sentido, Bobbio (2004, p. 5) ressalta que "Os direitos do homem, por mais fundamentais que sejam, são direitos históricos, ou seja, nascidos em certas circunstâncias, caracterizadas por lutas em defesa de novas liberdades contra velhos poderes, e nascidos de modo gradual, não todos de uma vez e nem de uma vez por todas."

A elevada complexidade e dinamicidade das situações fáticas faz com que as normas jurídicas se simplifiquem para se tornarem capazes de abarcar múltiplas situações fáticas, ainda que não completamente (LARENZ, 1997, p. 293-294). Nos casos em que inexiste uma lei correspondente a um dado problema jurídico, o magistrado deve recorrer à analogia ou ao direito advindo dos usos e costumes, buscando respostas também nos princípios jurídicos (REALE, 1999, p. 62).

O magistrado não pode, portanto, quando da análise de casos concretos, operar utilizando-se de meros dados lógico-formais, não podendo ser "a encarnação desse mundo abstrato de normas, prolatando sentenças como puros atos de razão", uma vez que também participa do meio social 
e deve examinar essas circunstâncias em uma visão concreta de experiência jurídica. Sentenciar não seria um ato meramente racional, porque exige a atitude de estimativa do juiz diante da prova e do próprio texto normativo (REALE, 1999, p. 136).

Silva (2003, p. 615-616) afirma que "texto e norma não se confundem, pois o primeiro é apenas um enunciado linguístico, enquanto que a norma é o produto da interpretação do enunciado." Grau (2006, p. 27-30), por sua vez, diz que a partir do conjunto dos fatos e do texto normativo é possível se obter a norma de decisão, esta que se destina a solucionar o caso. A partir de tal exercício é que se garante, conforme o autor, a concretização do direito, mediante a solução de casos concretos. Assim, com base em um texto legal determinado, pode ser extraída mais de uma solução jurídica para problemas diversos, de modo que, diante de um determinado caso concreto, o jurista precisa construir o significado do texto normativo aplicável ao caso concreto. A Ciência do Direito, portanto, busca construir a norma jurídica em sua situação concreta, pelo que se caracteriza enquanto ciência interpretativa, por destinar-se à interpretação do texto normativo com vistas à aplicação prática (FERRAZ JÚNIOR, 2009, p. 14).

No que se refere à interpretação, esta tem como tarefa "concretizar a lei em cada caso", ou seja, construir a norma do caso concreto, e é reservada ao juiz, que se submete, contudo, à lei, assim como os demais membros da comunidade jurídica (GADAMER, 1997, p. 489). A referida norma de decisão, ou norma do caso concreto, não existe previamente ao caso, mas é construída a partir de normas jurídicas e elementos fáticos referentes ao caso cuja solução se requer. É o que explica Muller (2009, p. 148):

A norma jurídica não está nem pronta nem é simplesmente passível de ser apli-
cada. Ela funciona no caso particular determinado de um modo que poderia ser
resumidamente qualificado como "aplicação". Ela modifica o teor de sua forma-
ção com cada caso para o qual é conquistada por meio da atividade dos órgãos
de decisão. A norma de decisão é o estado de agregação mais individualizado da
norma jurídica, e não uma entidade autônoma situada ao lado dela.

Para que possam ser aplicadas a casos concretos, as normas jurídicas são interpretadas. Sobre essa interpretação, Larenz (1997, p. 293-294) ensina que:

No começo, está o texto da lei - só aparentemente claro e fácil de aplicar - e no final - se este existe -, entretecida em torno do texto, uma teia de interpretações, restrições e complementações, que regula a sua aplicação no caso singular e que transmudou amplamente o seu conteúdo, a pontos de em casos extremos quase o tornar irreconhecível. Com efeito, um estranho resultado daquele processo que o jurista se habilitou a denominar simplesmente de aplicação das normas!

A norma jurídica, portanto, consiste em uma pluralidade de proposições que, embora sejam frases gramaticalmente completas, não se apresentam como proposições jurídicas completas. Dessa forma, a proposição preencheria "uma função auxiliar" para a compreensão de outras proposições jurídicas por ela prescritas, sejam estas completas sejam incompletas (LARENZ, 1997, p. 359-360). Além disso, as proposições jurídicas relacionam-se umas com as outras, conduzindo uma 
regulação, cabendo à jurisprudência elaborar o seu sentido (LARENZ, 1997, p. 370). A interpretação, por sua vez, inicia-se com conceitos prévios que podem ser substituídos por outros que se mostrem mais adequados. É o que explica Gadamer (1997, p. 403):

A compreensão somente alcança sua verdadeira possibilidade quando as opiniões prévias, com as quais ela inicia, não são arbitrárias. Por isso faz sentido que o intérprete não se dirija ao texto diretamente, a partir da opinião prévia que lhe subjaz, mas que examine tais opiniões quanto à sua legitimação, isto é, quanto a sua origem e validez.

Kelsen (1999, p. 248) frisa que não há como se extinguir a diversidade de interpretações dadas a normas jurídicas, contudo, seria necessário adotar medidas no sentido de minimizar tais divergências. Observe-se:

Não há absolutamente qualquer método - capaz de ser classificado como de direito positivo - segundo o qual, das várias significações de uma norma, apenas uma possa ser destacada como "correta" - desde que, naturalmente, se trate de várias significações possíveis [...] Todos os métodos de interpretação até o presente elaborados conduzem sempre a um resultado apenas possível, nunca a um resultado que seja o único, correto.

Como dito, a construção da norma de decisão, ou norma do caso concreto, não se restringe tão somente à interpretação da norma jurídica posta, perpassando pela realidade, sendo a verdadeira tarefa do juiz tratar esta última como parte da normatividade jurídica (MULLER, 2009, p. 151). Não é possível considerar, portanto, a separação absoluta entre norma jurídica e fato, posto que a partir da norma jurídica é que se constrói a norma jurídica do caso concreto objetivando alcançar uma solução, sendo tarefa do julgador providenciar essa construção quando da análise de um determinado caso.

Larenz (1997, p. 392-394) explica que o jurista recebe para julgamento uma situação de fato "bruta", por meio de um relato. A partir daí, deve o jurista encurtar e complementar o relato original, mediante a coleta de provas, até construir o enunciado do fato, caracterizando os eventos que integram o caso a ser analisado. A problemática reside exatamente na constatação de que os enunciados de fatos se apoiam em percepções próprias ou de terceiros. $\bigcirc$ juiz não presencia os fatos dos casos que julga, em regra os apreende por meio de relatos de terceiros, pelo que deve examinar a relevância jurídica dos fatos alegados e sua verossimilhança, mediante a contraposição do arcabouço probatório de cada processo, para, ao final, construir o enunciado mais adequado do fato (LARENZ, 1997, p. 394-395).

Traçando-se um paralelo com a obra cinematográfica Rashomon, é fácil observar as dificuldades que permeiam a atividade jurisdicional no sentido de extrair um enunciado de fato o mais próximo possível da realidade para o fim de construir a norma do caso concreto, ou norma de decisão. A situação fática não se apresenta de forma clara e precisa, de modo a automaticamente atrair a aplicação de uma determinada norma jurídica, como no modelo de subsunção, que se mostra em absoluto inadequado para a aplicação da norma jurídica, uma vez que esta não é entregue pronta, de modo a ser aplicada de forma lógica sem maiores dificuldades (MULLER, 2009, p. 230). Como em Rashomon, 
a situação fática apresenta-se por meio de múltiplos relatos a serem colhidos pelo julgador, cada um baseado em percepções próprias do narrador, cabendo ao juiz buscar a verdade, ou o que mais dela se aproximar, a partir do conjunto de provas.

Para Chamon (2008), a atividade do juiz está necessariamente ligada ao que foi construído e reconstruído no processo jurisdicional. Afirma o autor que "há que se envolver, há que se aprofundar no caso, e nos argumentos das partes, há que se entender o contexto e os pressupostos que sua decisão exigem, sem que isso signifique deixar de ser imparcial, mas, por outro lado, isso definitivamente não significa ser neutro." (CHAMON, 2008, p. 150). A pretensão de neutralidade, para o autor, é inviável, posto que o exercício da atividade jurisdicional implica uma necessária conexão com o Direito e a sociedade. É que, "como fruto da linguagem social, o magistrado conta com todos os seus pré-conceitos desde suas mais remotas experiências (conscientes ou não), de sua formação humana e jurídica, até os elementos probatórios que se deram no curso regular do processo." (RIBEIRO; BRAGA, 2016, p. 3387). A imparcialidade, portanto, não estaria relacionada diretamente ao fato de decidir em conformidade com a argumentação de alguma parte, mas com o rigor da fundamentação e da argumentação que motivam a decisão.

Necessário se faz, portanto, que haja uma coordenação entre o enunciado do fato e a norma geral, de modo a obter-se a norma de decisão, ou norma do caso concreto, bem como a adequação das medidas determinadas para a concretização da consequência jurídica prevista pela norma, a qual deve ser devidamente justificada e motivada por meio da fundamentação e argumentação jurídicas.

\section{Conclusão}

A problemática referente à percepção, as interferências e influências sofridas por esta conforme as condições de percepção e as características inerentes ao sujeito que percebe distanciam o "enunciado do fato" do "fato", na medida em que aquele é tão somente a expressão da percepção do sujeito que percebe este último. A verdade é, dessa forma, frágil. A obra cinematográfica Rashomon, analisada na primeira seção do presente estudo, ilustra perfeitamente como a percepção, bem como a interferência de fatores diversos modificam a narrativa do fato, de modo que o relato não retrate de forma fidedigna o fato que efetivamente ocorreu. A ausência de identificação da versão que traduz a realidade, ao final do filme, sugere que nem sempre a verdade pode ser alcançada.

Não se pode, contudo, admitir que o sistema jurídico se baseie tão somente na verdade, o que seria uma concepção utópica, e nem se pode admitir, de igual modo, o total desprezo da verdade, que implicaria arbitrariedades. A fragilidade da busca pela verdade não pode ser considerada como obstáculo à sua persecução, sendo necessário buscar a sua aproximação máxima, a partir do enunciado do fato e das provas que permeiam o objeto investigado.

As previsões determinadas do texto normativo não esgotam a totalidade das condutas humanas, notadamente em razão da complexidade e dinamicidade das relações sociais e situações 
fáticas que requerem apreciação jurídica. $\bigcirc$ texto normativo se simplifica de modo a abarcar a maior quantidade possível de situações fáticas, ainda que não completamente. Cabe ao juiz, portanto, diante de casos concretos, por meio do conjunto dos fatos e do texto da norma jurídica, construir a norma de decisão, ou norma do caso concreto, esta que se destina, como o próprio nome sugere, a solucionar o caso. A partir dessa construção é que se concretizam os direitos. A construção da norma do caso concreto não se restringe, portanto, tão somente à interpretação da norma jurídica posta no texto, perpassando pela realidade, a qual deve ser tratada pelo magistrado como parte da normatividade jurídica.

Assim, a atividade do juiz está necessariamente ligada ao que foi construído e reconstruído no processo jurisdicional, devendo o magistrado envolver-se e aprofundar-se no caso e nos argumentos das partes, bem como nas provas colhidas, coordenando o enunciado do fato e a norma geral, de modo a obter a norma de decisão, ou decisão do caso concreto, bem como a adequação das medidas que determinará para a concretização de direitos.

\section{Referências}

AKUTAGAWA, Ryunosuke. Rashomon e outros contos. Tradução Madalena Hashimoto Cordaro e Junko Ota. São Paulo: Hedra, 2008.

BOBBIO, Norberto. A era dos direitos. Tradução Carlos Nelson Coutinho. Rio de Janeiro: Elsevier, 2004.

CHAMON JÚNIOR, Lúcio Antônio. Teoria da argumentação jurídica. Rio de Janeiro: Lúmen Juris, 2008.

FERRAJOLI, Luigi. Direito e razão. São Paulo: Revista dos Tribunais, 2002.

FERRAZ JÚNIOR, Tércio Sampaio. A ciência do direito. São Paulo: Atlas, 2009.

GADAMER, Hans-Georg. Verdade e método. Tradução Flávio Paulo Meurer. 3. ed. Rio de Janeiro: Vozes, 1997.

GRAU, Eros Roberto. Ensaio e discurso sobre a interpretação/aplicação do direito. 4. ed. São Paulo: Malheiros, 2006.

HABERMAS, Jürgen. A ética da discussão e a questão da verdade. São Paulo: Martins Fontes, 2004a.

HABERMAS, Jürgen. Verdade e justificação, ensaios filosóficos. Tradução Milton Camargo Mota. São Paulo: Edições Loyola, 2004 b.

JUNG, Carl G. Chegando ao inconsciente. In: JUNG, Carl G. (Org.). O homem e seus símbolos. Tradução Maria Lúcia Pinho. 2. ed. especial. Rio de Janeiro: Nova Fronteira, 2008. p. 15-131.

KELSEN, Hans. Teoria pura do direito. Tradução João Batista Machado. São Paulo: Martins Fontes, 1999. 
KUROSAWA, Akira. Rashomon. Japão: Daiei, 1969. Filme (88 min).

LARENZ, Karl. Metodologia da ciência do direito. 3. ed. Lisboa: Calouste Gulbekizan, 1997.

MERLEAU-PONTY, Maurice. A fenomenologia da percepção. Tradução Carlos Alberto Ribeiro de Moura. 3. ed. São Paulo: Martins Fontes, 2006.

MULLER, Friedrich. Teoria estruturante do direito. 2. ed. São Paulo: Editora Revista dos Tribunais, 2009. v. 1.

NIETZSCHE, Friedrich. Sobre verdade e mentira. Tradução Fernando de Moraes Barros. São Paulo: Hedra, 2007.

REALE, Miguel. Filosofia do direito. 8. ed. São Paulo: Saraiva, 1999.

RIBEIRO, Fernando José Armando; BRAGA, Barbara Gonçalves de Araújo. Dos métodos interpretativos clássicos à hermenêutica filosófica: para uma aplicação dialógica e reflexiva do direito. Disponível em: <http://www.publicadireito.com.br/conpedi/manaus/arquivos/anais/salvador/fernando_ jose_armando_ribeiro-2.pdf>. Acesso em: 05 jun. 2016.

SILVA, Virgílio Afonso da. Princípios e regras: mitos e equívocos acerca de uma distinção. Revista Latino-Americana de Estudos Constitucionais, Belo Horizonte, n. 1, p. 607-630, jan./jun. 2003.

XEREZ, Rafael Marcílio. Concretização dos direitos fundamentais: teoria, método, fato e arte. Rio de Janeiro: Lumen Juris, 2014.

Data de submissão: 20 de junho de 2017 Avaliado em: 06 de agosto de 2017 (AVALIADOR A) Avaliado em: 29 de junho de 2017 (AVALIADOR B) Aceito em: 05 de setembro de 2017 
